\title{
PRODUTIVIDADE DO MELOEIRO EM FUNÇÃO DE CUTIVARES E ÉPOCAS DE SEMEADURA ${ }^{1}$
}

\author{
PAULO SÉRGIO LIMA E SILVA², KENY HENRIQUE MARIGUELE³, PAULO IGOR BARBOSA E SILVA ${ }^{3}$
}

\begin{abstract}
RESUMO - A região dos municípios Mossoró-Açu apresenta grande importância na produção de melão amarelo no estado do Rio Grande do Norte, com cultivos realizados de junho a novembro. Nesse período existem variações nos fatores climáticos, sugerindo a possibilidade de influência da época de semeadura sobre o comportamento do meloeiro. O objetivo do trabalho foi avaliar os efeitos de épocas de semeadura (19/8, 9/9 e 29/9 de 1999) e de cultivares (Rochedo, AF 646, Gold Pride, Gold Mine e Goldex) sobre a produtividade da cultura do meloeiro. Utilizou-se o delineamento de blocos ao acaso com três repetições e parcelas subdivididas. As épocas foram aplicadas às parcelas e as cultivares, às subparcelas. Não houve efeito da interação épocas de semeadura x cultivares nas características avaliadas. Quanto ao número total de frutos/ha (NTF), peso (kg/ha) total de frutos e número de frutos comercializáveis, as melhores cultivares foram Rochedo e AF 646; Rochedo, AF 646 e Gold Pride e AF 646, respectivamente. As cultivares não diferiram quanto ao peso $(\mathrm{kg} / \mathrm{ha})$ de frutos comercializáveis. A época de semeadura somente influenciou o NTF. A semeadura em 29/9 propiciou melhores resultados.
\end{abstract}

Termos de indexação: Cucumis melo L., melão amarelo, cultivares

\section{MELON PRODUCTIVITY AS A FUNCTION OF DIFFERENT CULTIVARS AND SOWING SEASONS}

ABSTRACT - The region comprised by the municipalities of Mossoró-Açu is quite important with regard to yellow melon yield in the State of Rio Grande do Norte, where melon crops are grown from June to November. During this period, variations in climatic factors occur, suggesting the possibility of sowing season influences on the behavior of melon plants. The objective of this work was to evaluate the effects of sowing seasons $(8 / 19,9 / 9$ and 9/29, 1999) and cultivars (Rochedo, FA 646, Gold Pride, Gold Mine, and Goldex) on melon plant productivity. A completely randomized blocks design with split-plots and three replicates was utilized. The seasons were considered as plots, and subplots consisted of cultivars. No effects of the interaction between sowing seasons $\times$ cultivars on the evaluated traits were observed. With regard to total number of fruits/ha (TNF), weight (kg/ha) total fruits, and number of marketable fruits, the best cultivars were, respectively, Rochedo and AF 646; Rochedo, AF 646 and Gold Pride; and, AF 646. The cultivars did not differ with regard to weight $(\mathrm{kg} / \mathrm{ha})$ of marketable fruits. The sowing season factor only influenced TNF. Seeding on $9 / 29$ provided the best results.

Index terms: Cucumis melo L., yellow melon, cultivars

A região nordestina brasileira é responsável por mais de $90 \%$ da produção de melão Inodorus, representado pelos tipos Amarelo, Pele-de-sapo e Orange flesh, do país. O Estado do Rio Grande do Norte é o maior produtor brasileiro e, em 1998, contribuiu com $91 \%$ da produção (Menezes et al., 2001). A região compreendida pelos municípios Mossoró-Açu apresenta relevante importância no que se refere à produção de melão. Nessa região, encontra-se uma grande variação no que se refere aos sistemas de produção do meloeiro. Existem desde pequenos produtores a grandes empresas agrícolas. Os níveis tecnológicos, incluindo cultivares e práticas culturais, são também bastantes variáveis. Na realidade, muitas das tecnologias praticadas com o meloeiro e com outras culturas foram importadas de outras regiões, até porque a citada cultura tem sido relativamente pouco estudada no Rio Grande do Norte. Assim, muitas práticas culturais são adotadas após tentativas por vários agricultores.

Na referida região, o meloeiro é cultivado fora do período das chuvas, mais ou menos de junho/julho a novembro/dezembro, com irrigação por gotejamento. Como a cultura apresenta ciclo em torno de 60 dias, vários cultivos podem ser feitos em cada ano. Na região, durante o citado período, as variações dos fatores climáticos não são grandes, mas existem, sugerindo a possibilidade de efeito de época de semeadura sobre o comportamento do meloeiro. Aliás, os agricultores informam que, aparentemente, existem variações no rendimento, nas dimensões dos frutos e em outros atributos dos frutos do meloeiro, durante os vários períodos de cultivo.

Não foram encontrados, na literatura consultada, muitos trabalhos sobre os efeitos da época de semeadura no meloeiro. Um dos fatores que contribui para isto certamente é o fato de que, em muitas regiões, por limitações climáticas, o meloeiro é cultivado uma só vez por ano. Saglan e Yazgan (1997) verificaram que a produtividade ( $\left.\mathrm{t} \mathrm{ha}^{-1}\right), \mathrm{o}$ número de frutos/planta e o peso médio do fruto do meloeiro Cucumis melo var. flexuosus Naud, foram alterados pela época de semeadura.
Rezende et al. (2003) verificaram efeito de época de plantio no desempenho de dois híbridos de melão rendilhado, em cultivo protegido. Em melancia (Citrullus lanatus Thunb.), Rajput et al. (1990) verificaram que a época de semeadura promoveu alterações na produtividade (t.ha$\left.{ }^{1}\right)$ da cultura, em razão de alterações no peso médio de frutos, número de frutos por planta e número de ramos por planta. Também em outras frutíferas verificou-se efeito de época de plantio (Cunha et al., 1993).

Diante do exposto, realizou-se este trabalho com o objetivo de avaliar os efeitos de épocas de semeadura (19/8, 9/9 e 29/9 de 1999) e de cultivares (Rochedo, AF 646, Gold Pride, Gold Mine e Goldex) sobre a produtividade da cultura do meloeiro.

Realizou-se o experimento na empresa "Agrícola Cajazeira", localizada no município de Tibau-RN, distante $30 \mathrm{~km}$ da sede do município de Mossoró-RN (latitude $5^{\circ} 11^{\prime} \mathrm{S}$, longitude $37^{\circ} 20^{\prime} \mathrm{W}$ e altitude de $18 \mathrm{~m}$, aproximadamente), principal cidade da região Oeste Potiguar. Dados sobre os fatores climáticos ocorridos na região durante o período do semeio à colheita para cada época de semeadura avaliada encontram-se na Tabela 1.

O solo, um Argissolo Vermelho-Amarelo (Podzólico VermelhoAmarelo), foi preparado com uma aração e duas gradagens e recebeu, como adubação de plantio, cerca de $10 \mathrm{t} /$ ha de esterco bovino curtido, em sulcos com a profundidade aproximada de $0,20 \mathrm{~m}$. Após a aplicação do esterco, os sulcos foram cobertos com solo. A análise do solo indicou: $\mathrm{pH}=7,5 ; \mathrm{em} \mathrm{cmol} / \mathrm{dm}^{3}: \mathrm{Ca}=6,80 ; \mathrm{Mg}=0,90 ; \mathrm{K}=0,38 ; \mathrm{Na}=0,29 ; \mathrm{Al}=$ 0,$00 ; \mathrm{P}=43 \mathrm{mg} / \mathrm{dm}^{3}$. A semeadura foi feita à profundidade de $1,0 \mathrm{~cm}, \mathrm{em}$ covas abertas onde foi aplicado o esterco. Aos cinco dias após a semeadura realizou-se um replantio para redução do número de falhas.

As cultivares Gold Mine, Rochedo, Gold Pride, AF 646 e Goldex foram semeadas em três épocas, de 20 em 20 dias, a partir de 19/08/1999. São cultivares híbridas muito semelhantes no que se refere a hábito de crescimento (indeterminado) e florescimento (de 28 a 35 dias). As cultivares Gold Mine e Rochedo possuem ciclo em torno de 65 dias.

\footnotetext{
(Trabalho 007/2003). Recebido: 10/01/2003. Aceito para publicação: 24/10/2003. Apresentado no XVII Congresso Brasileiro de Fruticultura.

${ }^{2}$ Eng. Agr., Dr.; Prof. Adjunto, Esc. Sup. Agric. Mossoró (ESAM). Cx. Postal 137 - 59625-900 - Mossoró-RN. Fone: (084) 312-2100. E-mail: paulosergio@esam.br. ${ }^{3}$ Estudante de Agronomia da ESAM. Cx. Postal 137 - 59625-900 - Mossoró-RN. Fone: (084) 312-2100. E-mail: paulosergio@esam.br.
} 
TABELA 1 - Médias de temperaturas máxima e mínima, da umidade relativa do ar e insolação por períodos do ciclo do meloeiro, observadas nas três épocas de semeadura em avaliação.

\begin{tabular}{|c|c|c|c|c|c|c|c|c|c|c|c|c|c|c|c|}
\hline \multirow{3}{*}{ Períodos } & \multicolumn{15}{|c|}{ Épocas de semeadura } \\
\hline & \multicolumn{5}{|c|}{ 19/8/1999 } & \multicolumn{6}{|c|}{ 9/9/1999 } & \multicolumn{4}{|c|}{ 29/9/1999 } \\
\hline & $\begin{array}{c}\text { Temp. } \\
\max . \\
{ }^{\circ} \mathrm{C}\end{array}$ & $\begin{array}{c}\text { Temp. } \\
\text { min. } \\
{ }^{\circ} \mathrm{C}\end{array}$ & $\begin{array}{c}\text { Umid. } \\
\text { rel. } \\
\%\end{array}$ & $\begin{array}{c}\text { Vel. } \\
\text { Vento } \\
\mathrm{m} / \mathrm{s}\end{array}$ & $\begin{array}{l}\text { Insol. } \\
\text { h/dia }\end{array}$ & $\begin{array}{c}\text { Temp. } \\
\max . \\
{ }^{\circ} \mathrm{C}\end{array}$ & $\begin{array}{c}\text { Temp. } \\
\text { min. } \\
{ }^{\circ} \mathrm{C}\end{array}$ & $\begin{array}{c}\text { Umid. } \\
\text { rel. } \\
\%\end{array}$ & $\begin{array}{c}\text { Vel. } \\
\text { Vento } \\
\mathrm{m} / \mathrm{s}\end{array}$ & $\begin{array}{l}\text { Insol. } \\
\mathrm{h} / \mathrm{dia}\end{array}$ & $\begin{array}{c}\text { Temp. } \\
\max \text {. } \\
{ }^{\circ} \mathrm{C}\end{array}$ & $\begin{array}{c}\text { Temp. } \\
\text { min. } \\
{ }^{\circ} \mathrm{C}\end{array}$ & $\begin{array}{c}\text { Umid. } \\
\text { rel. } \\
\%\end{array}$ & $\begin{array}{c}\text { Vel. } \\
\text { Vento } \\
\mathrm{m} / \mathrm{s}\end{array}$ & $\begin{array}{l}\text { Insol. } \\
\mathrm{h} / \text { dia }\end{array}$ \\
\hline $0-10$ & 34,9 & 21,9 & 54,0 & 4,4 & 10,0 & 35,2 & 23,5 & 61,0 & 5,0 & 9,6 & 34,9 & 23,0 & 58,6 & 4,7 & 10,6 \\
\hline $11-20$ & 35,6 & 22,5 & 55,9 & 4,9 & 10,7 & 35,5 & 23,3 & 61,2 & 5,0 & 9,9 & 35,3 & 23,2 & 61,4 & 5,1 & 10,5 \\
\hline $21-30$ & 35,2 & 23,5 & 61,0 & 5,0 & 9,6 & 34,9 & 23,0 & 58,6 & 4,7 & 10,6 & 33,6 & 24,0 & 64,5 & 5,0 & 9,1 \\
\hline $31-40$ & 35,5 & 23,3 & 61,2 & 5,0 & 9,9 & 35,3 & 23,2 & 61,4 & 5,1 & 10,5 & 35,4 & 24,2 & 62,3 & 4,9 & 10,1 \\
\hline $41-50$ & 34,9 & 23,0 & 58,6 & 4,7 & 10,6 & 33,6 & 24,0 & 65,4 & 5,0 & 9,1 & 34,7 & 24,4 & 67,7 & 5,1 & 9,7 \\
\hline $51-62$ & 35,3 & 23,2 & 61,4 & 5,1 & 10,5 & 35,4 & 24,2 & 62,3 & 4,9 & 10,1 & 33,6 & 23,7 & 69,4 & 4,1 & 8,9 \\
\hline Médias & 35,2 & 22,9 & 58,7 & 4,9 & 10,2 & 35,0 & 23,5 & 61,7 & 5,0 & 10,0 & 34,6 & 23,8 & 64,0 & 4,8 & 9,8 \\
\hline
\end{tabular}

Nas outras cultivares o ciclo varia de 60 a 65 dias. Todas possuem frutos com formato redondo-ovalado (os da Gold Pride são mais arredondados), casca de cor amarela-dourada levemente enrugada. Utilizou-se o delineamento de blocos completos casualizados com parcelas subdivididas e três repetições. Cada parcela ficou constituída por três fileiras com $6,6 \mathrm{~m}$ de comprimento. Como área útil, considerouse a ocupada pelas plantas da fileira central, eliminando-se uma planta em cada extremidade.

Utilizaram-se as práticas culturais adotadas na empresa, isto é, a densidade de plantio foi de 13.774 plantas/ha, adotando-se o

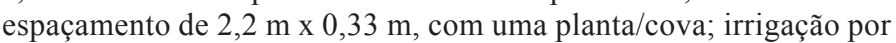
gotejamento, espaçando-se os gotejadores em $0,33 \mathrm{~m}$ na linha de plantio. A água de irrigação foi aplicada durante 2 horas do $1^{0}$ ao $5^{0}$ dia após o plantio (DAP); 1 hora do $6^{0}$ ao $12^{\circ}$ DAP e do $14^{0}$ ao $16^{0}$ DAP; 1,5 horas nos $18^{\circ}, 20^{\circ}$ e $22^{\circ}$ DAP; 2 horas no $25^{\circ}$ DAP; 2,5 horas do $26^{0}$ ao $30^{\circ} \mathrm{DAP} ; 3,5$ horas do $31^{0}$ ao $35^{\circ} \mathrm{DAP} ; 4,0$ horas do $36^{\circ}$ ao $40^{\circ} \mathrm{DAP} ; 5,0$ horas do $41^{\circ}$ ao $56^{\circ} \mathrm{DAP}$ e 3,5 horas do $57^{\circ}$ ao $63^{\circ} \mathrm{DAP}$. A quantidade d'água aplicada por hora foi de $23 \mathrm{~m}^{3} / \mathrm{ha}$. Os adubos (Tabela 2) foram aplicados via água de irrigação. As pragas e doenças foram controladas por pulverizações realizadas aos 12, 15, 20, 33 e 41 dias após a semeadura.

Duas colheitas foram realizadas no período de 60 a 67 dias após cada semeio. Foram avaliados os números e pesos de frutos, total e comercial, o comprimento e a largura dos frutos comercializáveis. Como comercializáveis foram considerados os frutos sem manchas e evidências aparentes de problemas fisiológicos ou do ataque de doenças e pragas. O comprimento e a largura dos frutos foram estimados medindo-se, com um paquímetro, todos os frutos comercializáveis de cada parcela. Os dados foram analisados pelo método da análise de variância e as médias comparadas a $5 \%$ de probabilidade, de acordo com as recomendações de Zar (1999).

Não houve efeito significativo da interação cultivares $\mathrm{x}$ épocas nas características avaliadas. Ao contrário do observado, Gurgel (2000) e Sena (2001), trabalhando sob condições semelhantes, verificaram efeito da interação genótipos de meloeiro $\mathrm{x}$ ambientes. Entretanto eles avaliaram grupos maiores de híbridos em maiores amplitudes ambientais.

As cultivares Rochedo e AF 646 apresentaram maior número total de frutos/ha, mas superaram apenas as cultivares Gold Mine e Goldex (Tabela 3). As cultivares Rochedo, AF 646 e Gold Pride foram as melhores quanto ao peso total de frutos, mas diferiram apenas da cultivar Goldex, a menos produtiva (Tabela 3). A cultivar AF 646 mostrou-se a mais produtiva em termos de número de frutos comercializáveis, mas somente diferiu significativamente da cultivar Goldex, a menos produtiva (Tabela 3). Também não houve diferenças entre cultivares quanto ao peso de frutos comercializáveis (Tabela 3 ). A cultivar Gold Mine superou todas as demais cultivares quanto ao comprimento médio dos frutos comercializáveis (Tabela 3). O menor comprimento foi apresentado pela cultivar AF 646. As demais cultivares apresentaram frutos com comprimento intermediário. A cultivar Rochedo suplantou a todas as demais cultivares quanto ao diâmetro dos frutos, as quais não diferiram entre si (Tabela 3 ).

A cultivar AF 646 mostrou-se superior em todas as características avaliadoras do rendimento de frutos. A cultivar Rochedo também apresentou comportamento promissor, exceto quanto ao número de frutos comerciais, em que ela não diferiu da cultivar menos produtiva (Tabela 3 ). As diferenças entre cultivares são devidas às diferenças genéticas, que manifestam-se em respostas distintas aos fatores ambientais, inclusive aos ataques de doenças e pragas. A superioridade das cultivares AF 646 e Rochedo foi observada por outros autores, na mesma região. Gurgel (2000) e Sena (2001) concluíram que ambas apresentam adaptabilidade ampla e estabilidade produtiva, mas que a cultivar Rochedo tende a apresentar menor produtividade (Sena 2001).

A semeadura mais tardia proporcionou maior número de frutos/ha que os plantios mais precoces, mas somente diferiu significativamente da primeira época de semeadura (Tabela 4). Temperaturas elevadas (entre 20 e $30{ }^{\circ} \mathrm{C}$ ), associadas à alta

TABELA 2 - Fertilizantes aplicados à cultura do meloeiro, durante o período de 62 dias após cada semeadura.

\begin{tabular}{|c|c|c|c|c|c|c|c|}
\hline \multirow[b]{2}{*}{$\begin{array}{l}\text { Dias após o } \\
\text { plantio }\end{array}$} & \multicolumn{7}{|c|}{ Fertilizantes (kg/ha) } \\
\hline & Uréia & $\begin{array}{l}\text { Cloreto de } \\
\text { potássio }\end{array}$ & $\begin{array}{l}\text { Sulfato de } \\
\text { potássio }\end{array}$ & $\begin{array}{l}\text { Nitrato de } \\
\text { cálcio }\end{array}$ & $\begin{array}{c}\text { Fosfato } \\
\text { monoamônico }\end{array}$ & $\begin{array}{l}\text { Ácido fosfóri- } \\
\text { co (1/ha) }\end{array}$ & $\begin{array}{l}\text { Nitrato de } \\
\text { potássio }\end{array}$ \\
\hline 01 a 05 & - & 1,25 & - & 1,25 & - & 1,67 & - \\
\hline 06 a 10 & 5,00 & 2,92 & - & 2,08 & - & 2,92 & - \\
\hline 11 a 20 & 7,08 & - & 5,42 & 4,58 & 4,58 & 5,00 & - \\
\hline 21 a 27 & 5,83 & - & 4,58 & 11,25 & 1,25 & 9,17 & 6,67 \\
\hline 28 a 37 & 4,58 & 4,58 & 6,67 & 7,50 & 9,17 & 6,67 & 4,58 \\
\hline 38 a 48 & 1,25 & - & 13,33 & 2,08 & - & 2,92 & - \\
\hline 49 a 62 & - & - & 15,83 & 0,83 & - & - & - \\
\hline
\end{tabular}


TABELA 3 - Médias do número total (NTF) e comercial (NCF) de frutos, produção total (PTF) e comercial (PCF) de frutos, comprimento (COMP) e diâmetro (DIAM) de frutos em função de cultivares de meloeiro ${ }^{1}$

\begin{tabular}{|c|c|c|c|c|c|c|}
\hline Cultivares & $\begin{array}{c}\text { NTF } \\
\text { (unid./ha) }\end{array}$ & $\begin{array}{c}\mathrm{NCF} \\
\text { (unid./ha) }\end{array}$ & $\begin{array}{c}\text { PTF } \\
(\mathrm{kg} / \mathrm{ha})\end{array}$ & $\begin{array}{c}\text { PCF } \\
(\mathrm{kg} / \mathrm{ha})\end{array}$ & $\begin{array}{c}\text { COMP } \\
(\mathrm{cm})\end{array}$ & $\begin{array}{c}\text { DIAM } \\
(\mathrm{cm})\end{array}$ \\
\hline Rochedo & $22.921 \mathrm{a}$ & $14.215 \mathrm{ab}$ & $48.030 \mathrm{a}$ & $34.227 \mathrm{a}$ & $18,2 \mathrm{~b}$ & $16,4 \mathrm{a}$ \\
\hline AF 646 & $22.673 \mathrm{a}$ & $15.338 \mathrm{a}$ & $44.438 \mathrm{a}$ & $32.024 \mathrm{a}$ & $17,1 \mathrm{c}$ & $15,3 \mathrm{~b}$ \\
\hline Gold Pride & $20.748 \mathrm{ab}$ & $12.321 \mathrm{ab}$ & $43.314 \mathrm{a}$ & $26.979 \mathrm{a}$ & $18,0 \mathrm{~b}$ & $15,5 \mathrm{~b}$ \\
\hline Gold Mine & $17.766 \mathrm{~b}$ & $13.798 \mathrm{ab}$ & $39.251 \mathrm{ab}$ & $31.153 \mathrm{a}$ & $19,5 \mathrm{a}$ & $15,5 \mathrm{~b}$ \\
\hline Goldex & $16.654 \mathrm{~b}$ & $11.674 \mathrm{~b}$ & $33.256 \mathrm{~b}$ & $24.405 \mathrm{a}$ & $18,0 \mathrm{~b}$ & $15,9 \mathrm{~b}$ \\
\hline C.V., \% & 24 & 24 & 24 & 24 & 5 & 4 \\
\hline
\end{tabular}

${ }^{1}$ Médias na mesma coluna seguidas pela mesma letra não diferem entre si, a $10 \%$ de probabilidade, pelo teste de Tukey.

TABELA 4 - Médias do número total (NTF) e comercial (NCF) de frutos, produção total (PTF) e comercial (PCF) de frutos, comprimento (COMP) e diâmetro (DIAM) de frutos em função da época de cultivo do meloeiro ${ }^{1}$

\begin{tabular}{|c|c|c|c|c|c|c|}
\hline $\begin{array}{c}\text { Épocas de } \\
\text { cultivo }\end{array}$ & $\begin{array}{c}\text { NTF } \\
\text { (unid./ha) }\end{array}$ & $\begin{array}{c}\text { NCF } \\
\text { (unid./ha) }\end{array}$ & $\begin{array}{c}\text { PTF } \\
(\mathrm{kg} / \mathrm{ha})\end{array}$ & $\begin{array}{c}\text { PCF } \\
(\mathrm{kg} / \mathrm{ha})\end{array}$ & $\begin{array}{c}\text { COMP } \\
(\mathrm{cm})\end{array}$ & $\begin{array}{l}\text { DIAM } \\
(\mathrm{cm})\end{array}$ \\
\hline $19 / 8$ & $18.009 \mathrm{~b}$ & $10.385 \mathrm{a}$ & $36.822 \mathrm{a}$ & $22.776 \mathrm{a}$ & $18,2 \mathrm{a}$ & $15,5 \mathrm{a}$ \\
\hline $9 / 9$ & $19.093 \mathrm{ab}$ & $16.157 \mathrm{a}$ & $40.081 \mathrm{a}$ & $35.302 \mathrm{a}$ & 17,9 a & $15,6 \mathrm{a}$ \\
\hline $29 / 9$ & $23.355 \mathrm{a}$ & $13.865 \mathrm{a}$ & $48.071 \mathrm{a}$ & $31.195 \mathrm{a}$ & $18,3 \mathrm{a}$ & $15,6 \mathrm{a}$ \\
\hline C.V., $\%$ & 19 & 39 & 22 & 40 & 3 & 4 \\
\hline
\end{tabular}

${ }^{1}$ Médias na mesma coluna seguidas pela mesma letra não diferem entre si, a $10 \%$ de probabilidade, pelo teste de Tukey.

luminosidade e baixa umidade do ar, proporcionam as condições climáticas favoráveis à boa produtividade da cultura e frutos de ótima qualidade (Pedrosa, 1992). Nas três épocas de cultivo avaliadas, as médias das temperaturas máximas foram superiores a $30^{\circ} \mathrm{C}$ e, portanto, superiores aos limites mencionados por Pedrosa (1992). Contudo, as temperaturas ocorridas na primeira época foram, no geral, maiores que aquelas ocorridas na segunda época e estas, maiores que as da terceira época. Portanto, as menores temperaturas ocorridas a partir da terceira semeadura podem ter sido mais favoráveis à produtividade das cultivares. Por outro lado, os valores da umidade relativa do ar foram maiores durante o cultivo da terceira época e menores que aqueles da primeira época, enquanto os valores do cultivo da segunda época foram mais ou menos intermediários aos dos outros dois cultivos. Portanto, em termos de umidade relativa do ar e de acordo com as informações de Pedrosa (1992), a terceira época seria menos favorável à produtividade do meloeiro. Deve ser ressaltado que esses fatores climáticos interagem, dificultando uma análise isolada da ação de cada um deles sobre o comportamento do meloeiro (Whitaker e Davis, 1962). Apesar da tendência de semeaduras mais tardias propiciarem maiores pesos totais de frutos, as diferenças observadas não foram significativas (Tabela 4). Não houve diferenças entre épocas de semeadura sobre o número, peso, comprimento e diâmetro dos frutos comerciais.

À semelhança do observado no presente trabalho, Saglan e Yazgan (1997), trabalhando com melão Inodorus, observaram efeitos de época de semeadura sobre o peso ( $\mathrm{t} / \mathrm{ha})$ e o número de frutos/ planta, mas não sobre o comprimento dos frutos. Por outro lado, diferentemente do observado neste trabalho, eles constataram efeito de época de semeadura sobre o diâmetro do fruto.

Não houve efeito da interação épocas de semeadura $\mathrm{x}$ cultivares, sobre as características avaliadas.

A cultivar AF 646 mostrou-se a mais promissora quanto às características do rendimento de frutos.

As cultivares Gold Mine e Rochedo produziram frutos com maiores comprimento e diâmetro, respectivamente.

A semeadura realizada ao final de setembro propiciou melhor número total de frutos que a semeadura em épocas anteriores, mas a época de semeadura não influenciou outras características avaliadas.

\section{REFERÊNCIAS BIBLIOGRÁFICAS}

CUNHA, G.A.P. da; REINHARDT, D.H.R.C.; CALDAS, R.C. Efeito da época de plantio, tamanho da muda e idade da planta na indução floral sobre o rendimento do abacaxizeiro 'Pérola' na Bahia. Revista Brasileira de Fruticultura, Jaboticabal, v. 15, n.3, p.43-50, 1993.

GURGEL, F. de L. Adaptabilidade e avaliação qualitativa de híbridos de melão amarelo. 2000. 33f. (Dissertação de Mestrado em Fitotecnia) - Escola Superior de Agricultura de Mossoró, Mossoró, 2000.

MENEZES, J.B., GOMES JÚNIOR, J. ARAÚJO NETO, S.E., SIMÕES, A.do N. Armazenamento de dois genótipos de melão amarelo sob condições ambiente. Horticultura Brasileira, Brasília, v.19, n.1, p.42-49, 2001.

PEDROSA, J.F. Cultura do melão. Mossoró: ESAM, 1992.35p.

RAJPUT, J.C.; PATIL, B.P.; PALVE, S.B. Response of watermelon (Citrullus lanatus Thunb.) variety Sugarbaby to different dates of sowing in Konkan. Seeds \& Farms, v.16, n.1-2, p.9-10, 1990.

REZENDE, B.L.A., CANATO, G.H.D., CECÍLIO FILHO, A.B. Produção de híbridos de melão rendilhado, em cultivo protegido, em duas épocas de plantio. Horticultura Brasileira, Brasília, v.21, n.2, p.284, 2003. (Suplemento 1).

SAGLAM, N.; YAZGAN, A. The effect of sowing date and harvesting intervals on the yield of snake cucumber (Cucumis melo var. flexuosus Naud) as second crop. In: INTERNATIONAL SYMPOSIUM ON CUCURBITS, 1., 1997, Adana, Proceedings... Adana: International Society for Horticultural Science, 1997. p.245-252.

SENA, L.C.N. de. Adaptabilidade ambiental e estabilidade produtiva de híbridos de melão amarelo em oito ambientes da mesorregião Oeste Potiguar. 2001. 45f. Dissertação (Mestrado em Fitotecnia) - Escola Superior de Agricultura de Mossoró, Mossoró, 2001.

WITTAKER, T.W.; DAVIS, G.N. Cucurbits: botany cultivation and utilization. London: Leonard Hill, 1962. 250 p.

ZAR, J.H. Biostatistical analysis. 4.ed. Upper Saddle River, Prentice Hall, 1999. 663p. 